\title{
Configuración regional del Estado: Orden mercantil y comunidad interpretativa en la frontera México-Guatemala
}

\section{Regional State configuration: The mercantile order and interpretive community on the Mexico-Guatemala border}

Recibido el 25 de febrero de 2016.

Aceptado el 18 de agosto de 2016.

*Autor para correspondencia: Hugo Saúl Rojas Pérez, correo electrónico: hugosaulrojas@gmail.com

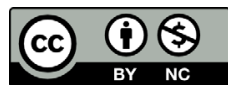

Todos los contenidos de Estudios Fronterizos se publican bajo la licencia Creative Commons Atribución no comercial 2.5 México, y pueden ser usados gratuitamente para fines no comerciales, dando el crédito a los autores y a la revista Estudios Fronterizos.
Hugo Saúl Rojas Pérez ${ }^{\mathrm{a}^{*}}$ (i) (http://orcid.org/0000-0002-4273-1640) Héctor Bernabé Fletes-Ocón ${ }^{a}$ (i) (http://orcid.org/0000-0001-5603-1808)

\begin{abstract}
${ }^{a}$ Universidad Autónoma de Chiapas, San Cristóbal de las Casas, Chiapas, México, correos electrónicos: hugosaulrojas@gmail.com, hctrfo@gmail.com
\end{abstract}

\section{Resumen}

Ofrecemos una descripción etnográfica de la circulación de hortalizas en la frontera de México con Guatemala. Estas mercancías transitan de un país a otro por caminos de extravío mediante tráfico hormiga: ingresan por medio del contrabando de pequeñas cantidades de manera constante, utilizando pasos fronterizos tolerados. El objetivo es mostrar cómo las interacciones de los actores fronterizos involucrados construyen un orden local distinto al de los parámetros normativos del Estado. Un orden que se fundamenta en una serie de normas no escritas que guían las prácticas de cruce, creando así una "comunidad interpretativa". Se esclarecerá por qué el personal operativo de diversos niveles del gobierno mexicano encargado de la supervisión mercantil no está al margen de dicha comunidad, sino forman parte importante de ella; y cómo se configura empíricamente el Estado dentro de la misma, partiendo de la idea de que el Estado no es un ente totalizador y coherente.

Palabras clave: comercio fronterizo, orden local, comunidad interpretativa, construcción empírica del Estado, frontera México-Guatemala.

\section{Abstract}

We offer an ethnographic description of the circulation of vegetables on the border between Mexico and Guatemala. These goods move from one country to the other through ant-style piecemeal trafficking on misdirected paths: they enter constantly as contraband in small quantities, using tolerated border crossings. The objective is to show how the interactions between

CÓMO CITAR: Rojas, H. S. y Fletes-Ocón, H. B. (2017). Configuración regional del Estado: Orden mercantil y comunidad interpretativa en la frontera México-Guatemala [Regional State configuration: The mercantile order and interpretive community on the Mexico-Guatemala border]. Estudios Fronterizos, 18(35), 1-21, doi: 10.21670/ref.2017.35.a01 
the border actors involved construct a local order that is different from that of the State's normative parameters. An order is founded on a series of unwritten rules that govern the practices of crossing, thereby creating an "interpretive community." This paper clarifies why the operating personnel from different levels of the Mexican government charged with overseeing trade are not outside of this community but rather compose an important part of it and how the State is empirically constructed within it, starting from the idea that the State is not an all-encompassing and coherent entity.

Keywords: border commerce, local order, interpretive community, empirical construction of the State, Mexico-Guatemala border.

\section{Introducción}

El artículo ofrece una descripción etnográfica en relación al control del comercio local de hortalizas en la frontera de México y Guatemala. ${ }^{1}$ Actualmente una de las principales actividades comerciales entre el Soconusco, Chiapas, México, y la región suroccidental de Guatemala es el flujo de hortalizas frescas de Guatemala a México. Este tipo de comercio circula de un país a otro por caminos de extravío mediante "tráfico hormiga"; es decir, ingresan por medio del contrabando de pequeñas cantidades, pero de manera constante, utilizando pasos fronterizos tolerados a pocos metros de las garitas oficiales. El artículo parte de la descripción de los mecanismos de cruce de comerciantes y productos por los pasos fronterizos, con el objetivo de mostrar cómo mediante las interacciones de los actores fronterizos involucrados se construye un orden local distinto al de los parámetros normativos del Estado.

La investigación se desarrolló entre los años 2011 a 2015, en dos cruces fronterizos, el primero Tecún-Umán (Guatemala) con Ciudad Hidalgo (México), y el segundo en El Carmen, Guatemala y Talismán, México; así como en la ciudad de Tapachula. ${ }^{2}$ A partir de la técnica de observación participante y entrevistas en torno al comercio, se evidenció la existencia de un orden local no reconocido oficialmente que permite el intercambio mercantil, en el que paradójicamente contribuye el personal operativo de instituciones de gobierno mexicano idealmente encargado de imponer el orden fronterizo oficial. Se mostrará cómo las prácticas llevadas a cabo por burócratas y personal de las instancias gubernamentales se alejan sustancialmente del discurso normativo de orden legal que enarbolan o en el que supuestamente se basa la lógica estatal. Lo que nosotros argumentamos es que, en sus

\footnotetext{
${ }^{1}$ El presente trabajo se basa en la tesis doctoral de Hugo S. Rojas Pérez titulado "Cuando el comercio hace la vida: orden negociado, transfiguración del valor y nacionalismo en el contexto fronterizo México-Guatemala", presentado en la Universidad Iberoamericana en febrero de 2014. La investigación inició en 2009, tiempo en el que se recopilaron algunas notas periodísticas. Los datos etnográficos se retomaron de su trabajo de campo llevado a cabo durante todo el año de 2011 y parte de 2012 y 2013. Posteriormente, en 2015, se realizó el trabajo de campo basado en entrevistas a profundidad dirigido por Héctor Fletes Ocón, principalmente en Ciudad Hidalgo en donde se encuentran varias instituciones de gobierno federal y municipal.

${ }^{2}$ El Soconusco constituye una región histórica (integrada hoy por 15 municipios), cuyos orígenes se pueden rastrear en la Mesoamérica prehispánica (Linares, 2010; Voorhies, 1991). En este periodo, la región abarcaba desde el Istmo de Tehuantepec (Oaxaca) a la actual frontera con Guatemala (Aubry, 2006, p. 95). Desde ese tiempo este territorio fue codiciado por ser un corredor estratégico de comunicación política y comercial entre dos regiones naturales y culturales de Mesoamérica, la parte occidental (llamada Nueva España) y la parte oriental (la audiencia de los Confines, hoy Centroamérica), separadas por la barrera geológica del Istmo de Tehuantepec (Aubry, 2006). Su peculiar condición de tránsito y asentamientos de pueblos indígenas en este periodo es modificada en la colonia al delimitarse su adscripción a la Capitanía General del Reino de Guatemala, siendo hasta mediados del siglo XIX que se vuelve a integrar a Chiapas y México (Castillo, 2002).
} 
prácticas como funcionarios públicos, policías fronterizos o supervisores fitosanitarios, ellos reinterpretan o modifican el orden normativo o bien lo adaptan a los criterios regionales de tráfico mercantil fronterizo, contribuyendo, de esta manera, a la generación de un orden de facto; el orden experimentado de forma cotidiana en los flujos mercantiles.

Nuestro acercamiento a la noción de Estado se realiza desde el método etnográfico y, por esta razón, es una visión descriptiva de tipo empírico. Es decir, dudamos de aquellas versiones que parten de la idea naturalizada de que el Estado es el resultado histórico de un pacto social donde los ciudadanos por su propia voluntad reconocen la existencia de una cúpula política, su autoridad moral, sus leyes, y fungen como los principales guardianes de dicho orden (Lagi, 2011, p. 5). De igual manera, nos distanciamos de las versiones que ven en el Estado un cuerpo burocrático sustentando en conocimientos de los cuales mana una administración racionalizada del poder (Mathews, 2006, p. 136). Más bien los datos etnográficos se inclinan a suponer que el Estado no es un aparato burocrático que se caracterice por tener una lógica racional apoyada en probadas tecnologías de poder homogéneas ni tampoco posee la legitimidad incondicional por parte de los ciudadanos que forman la comunidad política. Evidenciamos que hay una configuración regional del Estado que responde al contexto local y se fundamenta en el reconocimiento por parte de los sujetos fronterizos de la existencia de un orden de facto guiado por normas de tráfico no escritas; normas reconocidas como válidas tanto por los comerciantes dedicados al tráfico hormiga como por el personal burocrático y operativo del gobierno mexicano.

En el artículo se expondrá cómo los gobiernos en sus diferentes niveles político administrativos, hasta el momento de la investigación, no habían logrado generar consensos entre la población fronteriza sobre su exclusividad o su fuerza unívoca en el control binacional de los flujos mercantiles. En este contexto de frontera, deducimos que la capacidad del Estado como fuerza reguladora general no estriba en la aplicación de sus leyes reglamentarias (marco normativo), ni siquiera del consenso que pudieran tener sus categorías legales en la población fronteriza, sino de su legitimidad como autoridad moral para gestionar el orden a partir de su personal operativo, cuya labor consiste en escuchar puntos de vista de los diferentes grupos involucrados y en pugna, interpretarlos y establecer acuerdos con la intensión de mantener ordenamientos flexibles en cuanto a la tolerancia del cruce mercantil de las hortalizas.

El propósito del artículo no es juzgar la carencia de efectividad del Estado como gobierno en su papel de fuerza ordenadora de los flujos mercantiles, sino simplemente patentizar cómo el orden se produce a partir de las relaciones cotidianas de los diversos grupos de poder local, las burocracias locales y el personal operativo de distintos niveles de gobierno.

Para comprender la trama fronteriza y la producción del Estado en dicho contexto, recurriremos, en primer lugar, a definir qué estamos comprendiendo por "Estado", la frontera, y el comercio fronterizo. En este ejercicio, sugerimos la existencia de una comunidad interpretativa sobre lo que se instituye la actividad del tráfico hormiga, se trata de una serie de normas no escritas pero que todos los involucrados reconocen como válidas. Una vez definida dicha noción, nuestro análisis apunta a esclarecer cómo se establecen las interacciones de los actores en el marco de la comunidad. Para cumplir con este objetivo se contextualiza de manera general la actividad mercantil fronteriza, posteriormente se presentan datos etnográficos donde se detalla quiénes son los involucrados, cuáles son sus actividades y sus estrategias mercantiles. Posteriormente, analizaremos dos niveles del orden local en el que se hace evidente la comunidad interpretativa. Al examinar cómo se negocian el orden local en sus 
dos niveles con sus respectivos actores y estrategias, se pretende esclarecer la forma en que se configura el Estado a nivel regional, y paralelamente sugerir cómo dicha configuración es el elemento principal que sustenta el flujo de las hortalizas por medio del tráfico hormiga.

\section{Enfoque teórico metodológico}

Como mencionamos en la introducción, partimos de una crítica a los análisis del Estado de tipo normativo donde se toma como un hecho universal su existencia real, sobre todo por su función "del deber ser" y, por lo tanto, cuando se describen articulaciones de poderes fácticos con el Estado, se tildan de relaciones de poder anárquicas al margen de la esfera de lo legal. En tales análisis se ofrecen las tradicionales dicotomías entre formalinformal, lícito-ilícito y las subsecuentes recetas correctivas para eliminar las anomalías y dirigir la informalidad a las vías formales (Ordóñez, 2007, p. 98). También queremos diferenciarnos de una posición etnográfica donde se analiza el contrabando como si se tratara de un proyecto alternativo, justificándolo como un derecho básico de la población, o incluso un libre comercio sin intervención gubernamental, interpretándolo como un acto contra hegemónicos conscientemente organizado desde una sociedad civil global en resistencia a las leyes del Estado neoliberal (Galemba, 2011, p. 340). En este tipo de investigaciones se resalta la capacidad de agencia de los comerciantes dando por hecho que son agentes sociales que actúan con plena conciencia política.

La premisa de la que partimos es que no existe tal conciencia política por parte de los comerciantes fronterizos con excepción de sus líderes gremiales, ni hay un poder totalizador, que produzca un "orden social homogéneo" o "aparato burocrático coherente" (Escalona, 2011, p. 48). Más bien como lo propuso Philips Abrams (2000) en sus notas sobre las dificultades de estudiar el Estado, sugerimos la idea de que el Estado no existe como entidad concreta, coherente y totalizadora; más bien hay un "sistema de estado [ $s i c]$ como gobierno [...] y un mito sobre la existencia de un Estado que se legitima de diversas formas en la sociedad" (Abrams, 2000, p. 80). Este mito, por un lado, se cobija en la ilusión de representar supuestos valores morales universales (democracia, igualdad, justicia, imparcialidad), pero, al mismo tiempo, se nos hace ver como una cosa concreta separado de la sociedad.

De acuerdo con nuestra comprensión del contexto in situ, la función del Estado como gobierno estriba en su papel de gestor en representación del Estado a través de su personal operativo y sus mandos medios. Son los oficiales sanitarios y aduanales quienes gestionan el orden local junto con otros grupos de poder. Pero, como atinadamente lo describe Abrams (2000), también mediante el discurso del mismo personal se contribuye a la creación mítica del Estado como fuerza de poder general. De esta manera tenemos un doble manejo o uso de la figura del Estado; en el discurso y en la práctica. En el discurso se fetichiza por su imagen de representación de poder general que se concretiza mediante los mecanismos del control fronterizo como aparato burocrático, político y policiaco, así como mediante su infraestructura física: edificios de inspección, garitas, patrullas, puntos de supervisión, laboratorios móviles, etc., esto, desde el punto de vista de los residentes fronterizos, está funcionando como un referente simbólico para decir: "ese es y ahí está el Estado". En contraste, en la práctica, el establecimiento del orden mercantil es algo que se contextualiza, se construye y se lleva a cabo mediante disputas permanentes entre distintos grupos de poder. 
Al realizar una etnografía del orden fronterizo, ponemos el énfasis en los discursos y prácticas tanto del personal de los gobiernos como de los otros grupos de poder involucrados. La finalidad es esclarecer la estrategia analítica que seguiremos la cual retomamos de Das y Poole (2008), quienes sugieren "distanciarse de la consolidada imagen del Estado como forma administrativa de organización racionalizada que tiende a debilitarse o desarticularse a lo largo de los márgenes territoriales y sociales [...]" (2008, p. 19), y de manera más precisa, reflexionan "acerca de cómo en el desarrollo de la vida cotidiana se moldean las prácticas políticas de regulación y disciplinamiento que constituyen aquello que llamamos Estado" (2008, p. 19).

\section{Comunidad interpretativa y arenas de disputa}

Retomando la sugerencia de Das y Poole (2008), exponemos cómo el tráfico fronterizo de hortalizas de Guatemala con dirección a México está sustentado en una comunidad interpretativa (Stanley Fish, citado en González, 2009, p. 234). Nos referimos a la premisa de que hay un trasfondo comprensivo común de normas no escritas las cuales guían las prácticas mercantiles de los sujetos fronterizos. Por ejemplo, el uso de expresiones lingüísticas sobre la legalidad y la moral ("chueco"-"derecho"), hasta estrategias muy puntuales sobre el cruce de mercancías por medio de tráfico hormiga. Desde luego, dicha comunidad interpretativa no está libre de reinterpretaciones de los propios actores que la validan, pues se basa en la precomprensión de un sistema de normas no escritas que se dan por sentado. Como parte de esta ambigüedad en la interpretación que hacen los sujetos fronterizos, a pesar de creer que son válidas las normas de la misma comunidad interpretativa, cuando se presentan circunstancias excepcionales se tiende a reinterpretarla a conveniencia, ya sea en negociaciones políticas explícitas o bien en la reproducción de las prácticas mercantiles cotidianas.

Para ilustrar de una manera más sencilla las interacciones entre los distintos actores involucrados en el marco de esta comunidad interpretativa, presentaremos el contexto fronterizo como si se tratara de una arena donde se despliegan prácticas político mercantiles mediante formas explícitas y simbólicas del poder con la intensión de ejercer, controlar y regular el flujo de hortalizas. Algunos actores involucrados forman parte de grupos de poder que reinterpretan y direccionan a su favor el trasfondo comprensivo común de normas no escritas. La arena será el espacio fronterizo donde se dan disputas por el control del tráfico, cuya intención será mantenerse en el oficio, dominar e imponer los significados para garantizar el orden más conveniente para cada uno de los grupos involucrados. Ahí se medirán las jerarquías de cada grupo con relación a otros que también quieren negociar el orden local.

De acuerdo con este recurso heurístico diseñado por Arjun Appadurai (1991, p. 33) (con base en su lectura de Pierre Bourdieu), hay que dejar claro que los grupos de poder (comerciantes al menudeo, empresarios, transportistas), el personal operativo y las burocracias locales, antes de disputar y negociar el orden local, tienen una posición preestablecida, producto de una combinación de factores como preponderancia en el sector comercial, estratificación social local, grupo étnico de pertenencia como: tipo de mercancías traficadas, cantidad de mercancías, mecanismos de cruce, puesto político o público ocupado. Es decir, los grupos que se confrontan ya les preceden posiciones jerarquizadas más o menos establecidas y reconocidas, y los ubican de antemano en mejores o peores posiciones dentro de la arena fronteriza: no tendrán el mismo peso para 
negociar los comerciantes guatemaltecos de verduras que cruzan junto con sus pequeñas cantidades de mercancía tres o cuatro veces a la semana, que un bodeguero traficante de cinco a diez toneladas de hortalizas por día.

Para mostrar la construcción del orden local a la luz de este recurso heurístico llamado arena de disputas, a continuación, detallamos algunas características generales del comercio en la frontera y de cada uno de los grupos involucrados. Esto nos dará una idea de las posiciones que ocupan en el contexto mercantil del tráfico hormiga al tiempo que evidenciará la manera en que se configura el Estado desde las prácticas y exactamente en qué normas no escritas se basa la comunidad.

\section{Los pasos de extravío y el tráfico hormiga}

En el puente que une Talismán, México, y El Carmen, Guatemala, el flujo de las personas es constante. Tricicleros, señoras con bolsas de mandado y trabajadores agrícolas se dirigen rumbo a México. Por debajo de esta vía de internación formal, fluye el río Suchiate, la demarcación natural que separa los dos países. A la vista de todas las personas que trabajan o transitan sobre las aceras del puente, se observa el trasiego de verduras en dirección a México. Los objetos están atados con unicel, y transportados por personas que van nadando, colgados en una tirolesa, o bien, sobre un neumático de tractor.

A 10 kilómetros aproximadamente de este sitio de cruce, se localiza el puente fronterizo Dr. Rodolfo Robles que une Ciudad Hidalgo y Tecún Umán, la conexión terrestre con mayor actividad comercial de la frontera. Ahí se ubican las instalaciones mexicanas del Servicio de Administración Tributaria y a 300 metros aproximadamente, el puente Suchiate II (el recinto fiscal y comercial más grande del gobierno federal mexicano en la frontera con Guatemala). En este mismo perímetro, también sobre los márgenes del rio Suchiate existen al menos tres pasos informales, llamados localmente "pasos de extravío": son embarcaderos de balsas improvisadas con neumáticos de tractor con unas vigas de madera como transporte acuático. Por estos medios se introducen pequeñas cantidades de mercancías a través de los pasos de extravío. En algunos casos, son cantidades pequeñas (200 kg aprox.) de hortalizas que viajan junto con su comerciante utilizando el servicio de los balseros; en otros casos son pedidos al mayoreo, que suman varias toneladas y son manejados por compañías de transportes, tricicleros y balseros del lado de México que realizan la operación desde las ciudades guatemaltecas hasta los mercados de la ciudad de Tapachula. En este caso, las toneladas de mercancías se fragmentan en varios bultos individuales para poder ser transportados por balsas, las cuales, no soportan más de una tonelada (Observación directa, marzo 2015). Decir tráfico hormiga no es un sinónimo de circulación de mercancías al menudeo, sino más bien se refiere al paso constante y cotidiano de pequeñas cantidades para complementar un lote de varias toneladas de mercancías. ${ }^{3}$

En las siguientes líneas enlistamos los actores involucrados, sus actividades y posiciones dentro de esta actividad.

\footnotetext{
${ }^{3}$ Se trata de zanahorias, cebollas, coles, lechugas, tomates, y tubérculos como las papas. Los pequeños comerciantes trafican cantidades de 200 a $300 \mathrm{~kg}$ cada tercer día. En cuanto al cruce de hortalizas al mayoreo, más que calcular lo transportado por las balsas, se realizó un conteo de los transportes de carga que distribuyen estas mercancías exclusivamente al mercado San Juan, el más grande de Tapachula, durante todo el mes de mayo de 2011 y una semana de marzo de 2015. Observamos camiones de carga de 3 y 3.5 toneladas distribuyendo hortalizas cinco días a la semana. Sobre estas cantidades de hortalizas observamos su disminución durante la temporada de lluvias (agosto, septiembre, octubre) y aumentan de nuevo en el mes de diciembre.
} 


\section{Pequeños comerciantes de hortalizas}

La verdura se transporta en el territorio guatemalteco, tanto en servicios de carga particulares como en camiones de pasajeros que llegan al cruce fronterizo del Carmen. Cargadores conocidos como "buzos", acarrean la mercancía desde esa terminal, cruzan el río a pie o con tirolesa atando las mercancías con un ceñidor o mecapal y las dejan unos metros después de la garita de Talismán en México. En ese momento unos tricicleros del lado mexicano cargan la mercancía y la suben a los trasportes de carga o de pasajeros, donde unos minutos después el comerciante también se subirá para dirigirse al mercado San Juan en Tapachula. Mientras transcurre esto por abajo del puente, en los retenes de migración los comerciantes cruzan legalmente y enseñan al oficial en turno su pase local, ${ }^{4}$ en algunos casos se saludan cordialmente como si se conocieran de tiempo atrás.

Las labores de este tipo de comercio de verdura se llevan a cabo entre todos los miembros de una parentela extensa (papás, hijos, primos, nietos, sobrinos, etc.). Se trata de grupos familiares originarios de cantones y pueblos en el departamento de San Marcos, Guatemala. Todos los sujetos con que tuvimos oportunidad de platicar son bilingües, se expresan con fluidez en español, y utilizan el mam entre paisanos. De acuerdo con nuestras observaciones, son las mujeres quienes organizan el trabajo del grupo familiar y administran el dinero. Específicamente durante el trabajo de campo se estableció una relación de amistad con el grupo familiar de Doña Carmen (50 personas aproximadamente). En 2011, esta señora tenía 51 años y viajaba tres veces a la semana entre su pueblo natal, San Andrés Chapil, la plaza de compra "del Mosquito" en San Pedro Sacatepéquez, el cruce fronterizo del Carmen-Talismán y el mercado San Juan en la ciudad de Tapachula.

\section{Los bodegueros en el cruce de Tecún Umán-Ciudad Hidalgo}

Otra modalidad de introducción es a través de proveedores. Son cadenas de distribución de verduras a granel con operación binacional vinculadas por servicios de trasportación, almacenamiento y logística de ambos lados de la frontera.

En los mercados de Tapachula, los pedidos de hortalizas son levantados por jóvenes de 15 a 18 años de origen guatemalteco que trabajan para bodegueros de Tecún-Umán en Guatemala. Su función consiste en enumerar el tipo de verduras, precio, cantidad y anotar en una libreta de mano el pedido. Estos datos los notifican a los empleados de las bodegas, mediante mensajes por medio de teléfono celular y en 2015 ya se realizaban mediante el sistema WhatsApp (Observación personal, marzo 2015).

En las bodegas ubicadas en el lado de Guatemala, a escasos 700 metros del puente fronterizo oficial, se preparan los pedidos de los clientes de Tapachula de acuerdo con los encargos. Ahí existe una serie de empleados para embalar las hortalizas y dejarlas listas para trasladarse a los embarcaderos, ahí ya esperan varias balsas agrupadas a sindicatos mexicanos para llevarlas al otro lado del río (Figura 1).

\footnotetext{
${ }^{4}$ El pase local es la FMVL(Forma Migratoria de Visitante Local) y FMTF(Forma Migratoria de Trabajador Fronterizo). FMVL es la forma migratoria que permitía la internación de guatemaltecos para visitar las poblaciones fronterizas de México hasta por tres días (Acuerdo que tiene por objeto establecer las reglas conforme a las cuales se otorgarán facilidades migratorias a los visitantes locales guatemaltecos, 2008).
} 
Figura 1: Diagrama de los flujos de hortalizas por actores minoristas y mayoristas

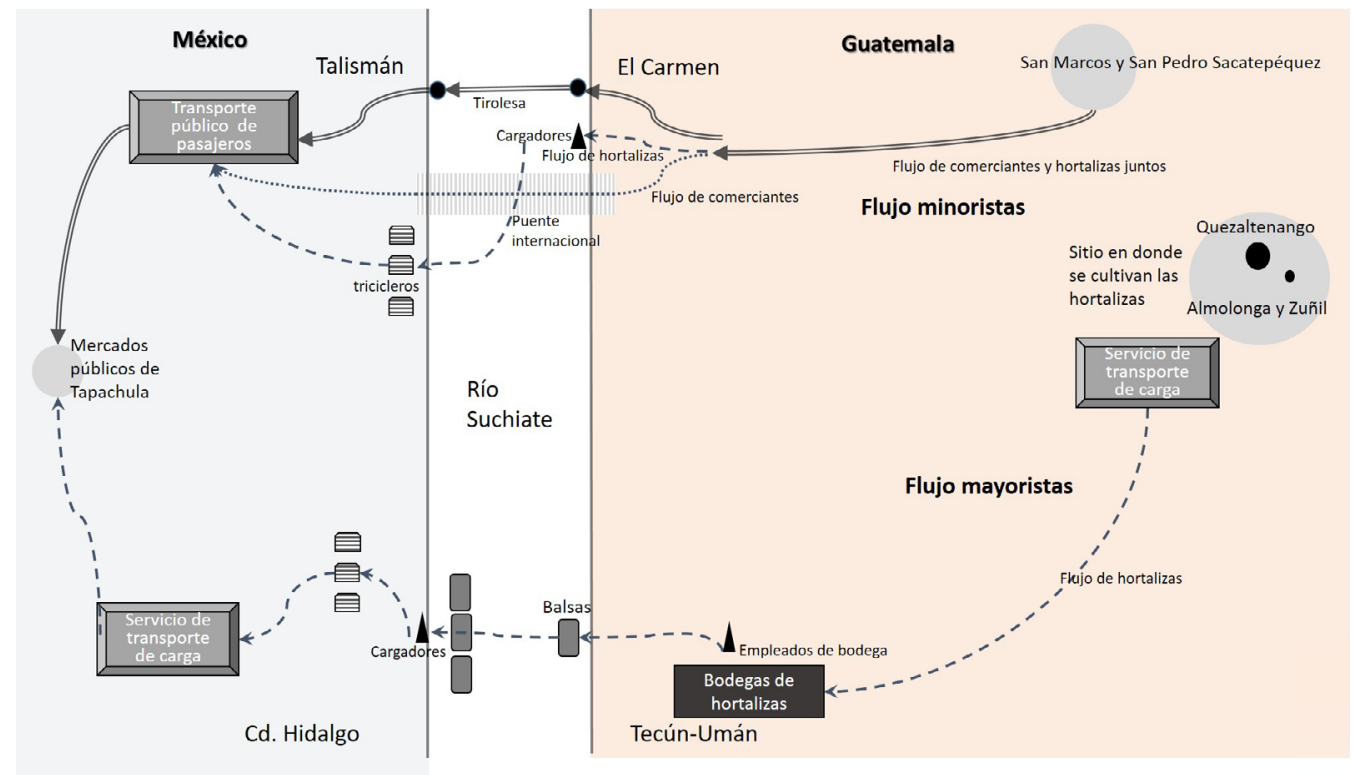

Fuente: Elaboración propia basada en las notas de campo.

Los dueños de las bodegas son grupos familiares política y económicamente preponderantes de la escena local del Suchiate y de Tecún Umán. En 2011 se contabilizaron cuatro bodegas y sus dueños eran expresidentes municipales de Suchiate (es decir, operan binacionalmente), ex líderes sindicales y sus familiares, quienes, aparte de estar al tanto de las contiendas de poder político municipal, se dedican a comercializar cantidades considerables de productos vegetales, así como de otras mercancías manufacturadas. Ellos, como grupo, funcionan mediante cadenas de distribución a granel con operación binacional vinculando servicios de transportación y logística de ambos lados de la frontera basados en afinidades de parentesco, pactos políticos, amistad y, por supuesto, el reconocimiento de una comunidad interpretativa que maneja las mismas expresiones lingüísticas sobre la moral y la legalidad.

En una entrevista que se realizó a Javier Ovando, un bodeguero de 45 años de edad, nacido en este sitio fronterizo, expresó lo siguiente:

Quiero el progreso de los dos países, pues mis parientes están en ambos lados de la frontera. Ciudad Hidalgo y Tecún Umán son pueblos hermanos donde la gente mantiene lazos consanguíneos y de amistad. Todos quienes viven en estas poblaciones su vida es el comercio que se da por los pasos de extravío, así que la mercancía que circula por aquí hacia Tapachula, aunque se crea que es ilegal, es algo secundario para nosotros. Lo ilegal es visto así sólo por el gobierno federal para cobrar más impuestos en sus aduanas. Eso aquí es secundario, pues se trata de una actividad derecha de la que comemos todos ricos y pobres de estos dos pueblos hermanos... Lo que comerciamos son bienes de primera necesidad que mantienen precios accesibles para la gente que tiene menos recursos (Ovando, 2015).

Javier Ovando ha sido regidor del municipio de Suchiate, actualmente se autodenomina empresario, porque forma parte de una reconocida cámara empresarial 
regional integrada a la Confederación de Cámaras Nacionales de Comercio, Servicios y Turismo (Concanaco Servytur), además de ser un líder local del Partido Verde Ecologista de México y anteriormente del Partido Revolucionario Institucional (notas de campo, 2015).

\section{Balseros y tricicleros en los pasos de extravío de Ciudad Hidalgo}

Los "balseros" tienen la función de cruzar las verduras de un lado a otro del río Suchiate, en este caso del lado guatemalteco a México. A simple vista, se pensaría que los tricicleros y los balseros son libres prestadores de servicios, no obstante, todos los balseros y tricicleros con los que se tuvo la oportunidad de conversar durante el trabajo de campo se agrupan en sindicatos incorporados a la Confederación de Trabajadores de México (CTM) o de la Confederación Regional Obrera Mexicana (GROM). Los dueños de las bodegas, también tienen una vida política muy activa como miembros de partidos políticos a nivel municipal. En Ciudad Hidalgo, estos prestadores de servicios reconocen abiertamente su afiliación al Partido Revolucionario Institucional (PRI) o el Partido Verde Ecologista de México, así como a los sindicatos. La posición política y de poder ocupados por estos personajes son muy limitados si se compara con los bodegueros. Los triciclos sirven como medios de publicidad de propagandas políticas y son la base para generar votos corporativos en las urnas por determinados candidatos.

Antonio, un empleado de un triciclo de 23 años, nos argumenta por qué no le convence ninguna de estas agrupaciones políticas y sin embargo debe tener una elección:

El sueldo es por alquiler, tú pagas 100 pesos diarios por el triciclo y el resto es para nosotros. El dueño pone la propaganda y nos invita a participar en las actividades del Partido, descontando el día del alquiler. Otros compañeros, con los que los patrones han trabajado por más tiempo se les sindicalizan y se les permite trabajar con triciclos o catarinas [motonetas de carga y pasajeros]... así que no hay otra más que pertenecer [al sindicato] y votar por el que te digan, ya que es prácticamente imposible trabajar sin preferencia política o sindical (Antonio, 2015).

\section{Trasportistas de carga}

Los "fleteros" se agrupan en diferentes sindicatos locales, todos de franca filiación priista. En las oficinas de un famoso sindicato de trasportistas de Suchiate instaladas en Ciudad Hidalgo, al preguntarle a su representante quiénes son las personas integrantes del sindicato, argumentó que todos los compañeros son de la zona fronteriza y más de la mitad son propietarios. Su afiliación se da mediante una cuota mensual, pero a cambio recibe algunas prestaciones sociales, puede transportar sin ser supervisado a profundidad, y en caso de requerirlo, recibir asesoría legal (Marco, 2015).

Platicando con un grupo de tres fleteros de este sindicato expresan que los propietarios de los vehículos son los que están afiliados, y ellos sólo son choferes que trabajan por flete. Señalaron que muchos de los propietarios son de Ciudad Hidalgo y también forman parte de familias renombradas de comerciantes. 
Lo que observamos en la vida comercial en los cruces fronterizos es cómo las mercancías (hortalizas y abarrotes) circulan utilizando este tipo de transportes en que se da una combinación de mecanismos informales de cruce, pero bajo el respaldo literal de instituciones políticas formalmente constituidas, como los sindicatos, partidos políticos y autoridades de gobierno municipal, lo cual evidencia cómo en las prácticas de este tipo de comercio fronterizo, se apela a la existencia de una comunidad interpretativa donde se desvanecen las dicotomías legal-ilegal, formal-informal (Castells y Porter, 1989).

\section{El gobierno federal: Los cercos fitosanitarios}

Durante la investigación se realizó observación en el puente aduanal Suchiate II y una serie de entrevistas estructuradas con el encargado de la Oficina de Inspección de Sanidad Agropecuaria en Puertos, Aeropuertos y Fronteras (Oisas) del Servicio Nacional de Sanidad Inocuidad y Calidad Agroalimentaria (Senasica), pertenecientes al gobierno federal. La función de estos filtros fitosanitarios ubicados en el recinto fiscal, según el jefe de la Oisas "es evitar el ingreso de plagas y/o enfermedades de importancia cuarentenaria y así salvaguardar la fitosanidad de nuestro país" (Salazar, 2015).

En observaciones participantes realizadas durante 2015, se evidenció que la Oisas tiene un papel muy acotado en lo referente a la regulación del cruce de alimentos vegetales por medio de tráfico hormiga, porque sólo se tiene control de inspección de lo que circula por los pasos legales: grandes cantidades de mercancías, ya sean vegetales en tránsito hacia los Estados Unidos o al mercado nacional, con su documentación en regla, pedimentos aduanales y pruebas de los laboratorios de fitosanidad previamente avalados por la Oisas. Mediante este tipo de procedimientos legales especializados salen beneficiadas unas cuantas empresas aduanales de servicios de gestión y de monitoreo de mercancía, dejando el control del tráfico hormiga a otros agentes de poder local.

\section{El personal operativo de inspección sanitaria de Senasica}

La Oisas, aparte de encargarse de los trámites burocráticos en cuanto a la supervisión legal de circulación de mercancías en el recinto fiscal de Suchiate II, posee personal operativo ubicado en puntos de inspección a un lado de las garitas de migración mexicana. Su función radica en revisar a las personas de quienes se sospecha de trasportar mercancías prohibidas. Mientras ellos desempeñan esta labor, a simple vista se puede observar debajo de los puentes de migración, tanto en El Carmen-Talismán como en Tecún Umán-Ciudad Hidalgo, la circulación habitual de mercancías. Cuando preguntamos a uno de estos oficiales por qué estas mercancías transitan sin control, explicó que siempre han existido esos flujos. Según la misma persona, el consumo recae en la cultura sanitaria de cada uno de los habitantes de esta ciudad y nos señaló: "yo como oficial sanitario, oriundo de la región, reparto volantes sobre los riegos biológicos de este tipo de actividad, pero no se tiene el personal suficiente como para prohibir totalmente" (Oficial de inspección Senasica, 2015).

Es posible que los puntos de inspección sanitaria sobre las carreteras que enlazan los cruces fronterizos y Tapachula sean los únicos sitios donde el personal operativo de la Oisas mantiene relaciones directas y cotidianas con los fleteros de hortalizas y pequeños comerciantes. En estos mismos cercos de inspección, por lo regular, se ubica la supervisión 
aduanal del Servicio Nacional de Administración Tributaria (sAT) y del Instituto Nacional de Migración (INM). Hemos observado cómo el personal en ese punto parte del supuesto de que quienes conforman este flujo son residentes locales del lado guatemalteco y ellos no son el objetivo de migración ni de aduanas (no son transmigrantes con destino a los Estados Unidos), pues la mayoría de los comerciantes como doña Carmen cuentan con pase local. Se realiza una supervisión visual por parte del personal de migración y se deducía a simple vista, sin tener un criterio bien definido, quién es transmigrante y quién no (notas de campo, noviembre de 2011).

En cuanto a los camiones de carga de hortalizas, en apariencia, en estos puntos, se emprende una mayor supervisión. No obstante, en la mayoría de nuestras observaciones, los camiones de fletes pasan lentamente, se les realiza una inspección visual o una revisión física de rutina, muy rápida.

Los cercos fitosanitarios representan, en este sentido, la intensión retórica del Estado por preservar la seguridad de la comunidad nacional con respecto a los peligros biológicos externos, aunque sus acciones en la práctica en cuanto al tráfico hormiga "son limitadas con respecto a sus ambiciosos ideales" (Mathew, 2006, p. 140; sobre regulación fitosanitaria y comercial c.f. Fletes, 2013a). Más bien, su papel en cuanto al control del tráfico hormiga, se basa en prácticas de negociación cotidiana entre su personal, fleteros y pequeños comerciantes de hortalizas. Si se interpretara desde una mirada normativa, parecería que las relaciones entre estos agentes estatales y los diversos agentes mercantiles reflejan la ausencia de control estatal y evidencian actos de corrupción de los ordenamientos legales. No obstante, lo observado es cómo el Estado se fabrica con base en el involucramiento de las burocracias y el personal operativo de gobierno en "formas de organización que se piensan informales o adversas a las lógicas del Estado" (Torres, 2005, p. 268).

\section{El gobierno municipal de Suchiate, Chiapas}

Estos flujos mercantiles de hortalizas no pasan inadvertidos por los servidores del gobierno municipal de Suchiate. Son ellos, en nombre del ayuntamiento, quienes propician una sensación de seguridad de los negocios para quienes se dedican al tráfico hormiga, por un lado, manejando un tipo de discurso sobre los significados de "derecho" aquí y por otro lado realizando rondines de vigilancia con su policía municipal en los pasos de extravío. No ven adecuado encasillar este tipo de comercio como "algo ilícito dañino al comercio establecido", sino como una actividad acostumbrada, producto de varios años de realizarse e incluso benéfica para toda la población fronteriza. Por esta razón, la argumentación de varios regidores a los cuales se entrevistó durante el 2015, es que se trata de "actividades derechas", y por lo tanto debe verse como un medio de vida honesto (notas de campo, abril de 2015).

Un argumento expresado en varias ocasiones por estos funcionarios municipales es ver el comercio de frontera como una actividad no caótica, sino como una economía ordenada por empresarios locales. Es una actividad tolerada, porque es una de las pocas fuentes de empleo para la población, y hasta el presente "el gobierno [el gobierno federal] no se ha preocupado" por generar fuentes de empleo alternativas a este tipo de actividades (Rojas, 2015).

Bajo este panorama, los diversos espacios analizados indican la manera en que los funcionarios del gobierno municipal se encargan de hacer seguros el cruce de mercancías 
alimenticias haciendo rondines de vigilancia por los pasos de extravío, supervisando la no entrada de mercancía "chueca", como armas y drogas, así como estableciendo cuotas de piso a los fleteros y comerciantes establecidos en Ciudad Hidalgo. En una entrevista, uno de los regidores, muy cercano al presidente municipal, también expresó algo similar a la postura común por todos los funcionarios municipales: "no debe mirarse el comercio de hortalizas y abarrotes como algo ilegal, es un flujo a pequeña escala básico para el consumo de la población mexicana y guatemalteca de escasos recursos" (Torres, 2015).

Fuera del tiempo de la entrevista y arriba de una patrulla municipal cuando realizaba un rondín por los pasos de extravío, el encargado de mercados y establecimientos mercantiles de Suchiate, comentó:

La policía vigila la actividad y su desarrollo normal, siempre y cuando no sean "cosas chuecas", es decir, tráfico de armas, drogas o lenocinio, porque en esos casos, no tenemos atribuciones y se canaliza al ejército mexicano, porque [...] afecta la actividad mercantil acostumbrada (Jaime, 2015).

El uso de derecho y chueco, es generalizado y el criterio es compartido de alguna forma entre todos los actores involucrados directa e indirectamente en este flujo, incluyendo los consumidores de la ciudad de Tapachula. Este hecho contribuye a crear un ambiente de tolerancia sobre el comercio de hortalizas por las vías ya mencionadas. Para el municipio es un flujo crucial si lo vemos desde la generación de empleos, servicios o recaudaciones. En realidad, las mismas autoridades municipales toleran la instalación de bodegas en sitios cercanos a los pasos de extravío y varias veces al año organizan ferias de comercio con empresarios de ambos lados de la frontera donde el criterio para definir formalinformal, lícito-ilícito es superfluo.

\section{Dos dimensiones del orden local}

Los discursos y las actividades de los actores mencionados anteriormente, muestran lo que algunos académicos guatemaltecos (Arriola, 1995; Ordóñez, 2007) y periodistas empezaban a denominar orden de facto: es decir, un funcionamiento mercantil basado en un orden local que fija la forma en que debe de gestionarse la circulación de mercancías por medio del tráfico hormiga. Se trata de un orden no estipulado en ley o reglamento alguno, pero compartido y experimentado en la vida cotidiana y sobre el cual se interrelacionan diferentes niveles de gobierno, población fronteriza y grupos de poder local (Mariscal, 2014; Ortiz, s.f.). Es un orden que puede ser interpretado más allá de una economía clandestina, puesto que el Estado, a partir de su representación en los burócratas gubernamentales y personal operativo, incide en la fabricación cotidiana de ese orden.

Para identificar específicamente cómo y cuándo se produce ese orden de facto, y cuál es la configuración regional del Estado, es preciso considerar que los actores fronterizos tienen posiciones preestablecidas en la arena de disputas del comercio. Estos posicionamientos de inicio son asimétricos, habrá actores como el personal operativo de gobierno federal, choferes, pequeños comerciantes; todos son generadores del orden de facto a un nivel empírico y cotidiano. En contraste, los bodegueros, introductores, líderes sindicales y los burócratas del gobierno confeccionarán desde arriba dicho orden, es decir, toman decisiones políticas para definir las reglas, además de experimentarlo en sus prácticas. Creemos que la complejidad que reviste la organización detrás del orden 
de facto puede ejemplificarse en dos niveles. El primer nivel es la manera en cómo este se experimenta en la vida cotidiana a través de una filosofía del orden, por ejemplo, por los pequeños comerciantes; y el segundo nivel es mirar este orden como una construcción de equilibrios y asimetrías, producto de negociaciones políticas (acuerdos explícitos e implícitos) entre gobiernos y grupos de poder, cuyas resoluciones se enfocan en establecer el grado de tolerancia de los cruces mercantiles.

A continuación, presentamos ejemplos de la manera en que se evidencian estos dos niveles del orden local y su articulación.

\section{El primer nivel: Lo chueco y lo derecho}

El grupo de actores antes descrito viven del comercio de tráfico hormiga y habitan esta fracción de frontera, y clasifican mercancías como "derechas" a todos aquellos productos vinculados a las necesidades alimenticias que circulan de un lado a otro. La circulación mediante el trasiego de productos alimenticios perecederos, reviste localmente una condición moral, "humanamente aceptable", si se le compara con la circulación de otros productos como son las drogas las cuales la vox populi indica que pasan por los mismos mecanismos de cruce, pero son "chuecas", no necesariamente por ser ilícitas según los parámetros oficiales, sino porque son objetos percibidos como dañinos a la salud. No obstante, estas categorías morales sobre la legalidad, basadas en subjetividades locales, en determinados momentos y a criterio de quien las utiliza, suelen intercalarse con las categorías normativas oficiales: lícito-ilícito. Lo que observamos es un marco de legalidad maleable, utilizado de forma pragmática. Todos los comerciantes pequeños, los grupos de poder mercantil y el mismo personal de gobierno, en general todo aquel sujeto fronterizo conocedor y con saberes sobre este manejo, utilizan las categorías como uno de sus gajes de oficio. El uso de la categoría está reflejando el reconocimiento por todos los actores fronterizos, de un marco de valores comunes, lo cual, les permite dar validez extraoficial al tráfico hormiga y generar una filosofía común sobre la legalidad.

Por ejemplo, para Doña Carmen, es positivo el comercio "tal y como está", porque favorece la economía de las "personas humildes", abarata las verduras al no haber tantos costos de "papeleo". No obstante, cuando se trata de drogas, en su opinión, "el gobierno debe prohibir su circulación, porque esos sí dañan" (Carmen, 2011).

Un comentario similar lo expresó un biólogo, empleado de los filtros fitosanitarios de la Senasica:

Es un tráfico ilícito pero honrado... Lo hacen comerciantes humildes, se ganan la vida con ese oficio. Sí, es verdad, viene mal la verdura, porque trae larvas, lo que indica su contaminación. Pero aquí existe una demanda de estos productos, y es difícil de erradicar. No es que estos guatemaltecos quieran meter su verdura por la fuerza a los mexicanos, sino es la falta de oferta y canales de comercialización de hortalizas mexicanas donde está la falla (González, 2011). ${ }^{5}$

\footnotetext{
${ }^{5}$ Cabe señalar que la observación constante que realizan distintos actores oficiales sobre el aspecto sanitario de las hortalizas guatemaltecas, está vinculada con la aplicación (siempre resistida y reconfigurada) de un paquete de términos y regulaciones sanitarias en diversos productos en la región Soconusco, del lado mexicano. La vigilancia oficial fitosanitaria constituye un proceso histórico (desde el primer cuarto del siglo $x x$ ) de relaciones entre agentes oficiales y los actores agrícolas empresariales y campesinos, en productos como café, plátano, algodón y mango (Fletes, 2013a).
} 
Daniel, otro empleado que labora en la coordinación regional de Sagarpa (Secretaría de Agricultura, Ganadería, Desarrollo Rural, Pesca y Alimentación), nos explicó: “del municipio de Motozintla, Chiapas, se traen productos como la papas, otras las traen de Distrito Federal o Puebla, pero debido al costo del trasporte son muy costosas". Cree que se consumen verduras guatemaltecas por su precio más económico y la gente de esta ciudad de Tapachula se acostumbró a ellas. Sobre la legalidad de estas mercancías comenta: "aunque pongamos más filtros y las vean de menor calidad en relación a las mexicanas, las verduras de Guatemala se van a seguir comprando, por el bajo poder adquisitivo de los tapachultecos y también por su falta de cultura sanitaria" (Daniel, 2011).

Para evidenciar otro de los elementos de la comunidad interpretativa, es importante resaltar cómo el personal operativo de la Senasica y Sagarpa que entrevistamos es originario de la ciudad de Tapachula o de los municipios aledaños. Es decir, este personal también contribuye a generar un clima de tolerancia al tener una visión del contexto similar a los comerciantes sobre el significado de lo derecho y chueco, además comparten los mismos conocimientos sobre los mecanismos del tráfico binacional. En todo caso, ellos fungen como amigos, cómplices o aliados de los comerciantes, y no solo como "garantes" del orden estatal.

Lo que queda al descubierto es que las dualidades: legal-ilegal, licito-ilícito, chuecoderecho son criterios deconstruidos en las relaciones cotidianas de los actores quienes comparten los mismos conocimientos y valores morales sobre el flujo aquí tratado. Incluso podríamos argumentar que la comunidad interpretativa se cristaliza directamente en las interpretaciones jurídicas reformuladas en eventos cotidianos, donde lo chueco y lo derecho tiene efectos ordenadores de formas similares a las categorías legal e ilegal. Queremos dejar en claro que, en las interacciones entre estos comerciantes y el personal operativo de gobierno federal, al presentarse simultáneamente las categorías émicas y oficiales, no se experimentan como elementos dicotómicos, sino como categorías complementarias, con mayor o menor validez según las circunstancias y la conveniencia.

\section{El segundo nivel: Disputas por el establecimiento del orden de facto "desde arriba"}

En el otro nivel de la arena de disputas, se negocia la tolerancia y los mecanismos de cruce. Se trata de acuerdos y concertaciones permanentes a partir de negociaciones explícitas e implícitas entre autodenominados empresarios (bodegueros de Ciudad Hidalgo e introductores de Tapachula), miembros de la Concanaco, Servytur, jefes aduanales y de migración, líderes sindicales, gobiernos municipales y medios de comunicación local. No podemos considerar a los empresarios y transportistas participantes en estas negociaciones como pequeños mercaderes que nada más experimentan la frontera, como el caso de Doña Carmen, sino son actores hegemónicos en el sentido de ser grupos de presión organizados con capacidad de negociación política con el gobierno federal.

Por ejemplo, en las notas periódicas de diarios locales; el Orbe y Diario del Sur citados textualmente en párrafos posteriores, se evidencia el poder de los transportistas y otros empresarios locales dedicados al negocio del trasiego fronterizo de alimentos. En primer lugar, estos líderes y empresarios, a través de boletines y notas periodísticas, se asumen como víctimas de las decisiones de un gobierno federal supuestamente inflexible, el cual los incita a "traficar", "contrabandear" y "cometer actos de corrupción". Estos "empresarios" arguyen falta de información sobre los procedimientos y marcos jurídicos 
para la introducción de mercancías de formas legales por los puentes fronterizos. En segundo lugar, al asumirse como ignorantes de las leyes y los procedimientos formales de cruce, de alguna manera deducen que el paso de mercancías por vías acostumbradas es moralmente válido. En tercer lugar, cuando sostienen reuniones con los mandos medios de gobierno federal (aduanas y Oisas) para solicitar información en relación al funcionamiento fronterizo desde la perspectiva gubernamental, en realidad, su pretensión es exigir una mayor flexibilidad para que sus actividades mercantiles trascurran sin trabas gubernamentales. En la siguiente nota periodística se reseña claramente esta posición:

En el marco del Primer Congreso de Cámaras del Sureste de México y Guatemala, el presidente de la Cámara Nacional de Comercio en Tapachula, Edmundo Olvera Cantera destacó que las autoridades hacen que el problema del contrabando de mercancías entre los dos países hermanos sea mayor, al no proporcionar información de trámites de exportación a los empresarios, además de realizar actos de corrupción al extorsionar a los traficantes. [...] Asimismo dijo, que con este tipo de eventos con la participación de las autoridades, se tiene la intención de que se les enseñe a todos los empresarios el cómo se puede traer y llevar la mercancía de manera legal y rápida. [...] Cabe destacar, que desde ayer y durante tres días más, las cámaras de comercio del sureste de México y de Guatemala sostendrán reuniones con autoridades para buscar la manera de poder hacer más flexible el intercambio (Flores, 2009).

Como notamos en esta narración periodística, se adjudica al gobierno la responsabilidad exclusiva del ambiente de corrupción experimentado en la frontera. Curiosamente ellos no asumen su complicidad en el trasiego, sino se muestran como honrados empresarios representantes de la sociedad civil. Estos empresarios se dicen ser los más afectados de las decisiones gubernamentales, las cuales se les imponen desde arriba y, por lo tanto, se ven orillados a utilizar métodos clandestinos. Al hacer el seguimiento del flujo mercantil de maíz, observándolo desde los discursos de un grupo de traficantes de maíz en la frontera de Comalapa, Chiapas, y la Democracia en Huehuetenango, Guatemala, Rebeca B. Galemba (2011), reproduce versiones similares a la que estos empresarios expresan en las notas periodísticas. A pesar del buen manejo teórico de la autora, la información de campo recopilada valida cómo efectivamente son estos traficantes de bienes alimenticios quienes "resisten las leyes hegemónicas del neoliberalismo" (2011, p. 397). Tanto la interpretación hecha por esta antropóloga como la nota periodística, las consideramos incorrectas para acercase a la complejidad del análisis empírico del Estado, dado que no se percatan de que los funcionarios de gobierno federal a nivel regional y este tipo de comerciantes todo el tiempo están en negociaciones y toman posiciones coyunturales, según las circunstancias que se presenten. Es decir, se representan en la arena de disputas como grupos antagónicos, pero en la realidad, hay negociaciones y cooperaciones entre actores, cada uno buscando su propio beneficio (c.f. Fletes, 2013b).

En nuestras observaciones empíricas sobre los "empresarios", encontramos un perfil similar; todos pertenecen a gremios incorporados a sindicatos como la CTM y la GROM y, a su vez, son representantes de cámaras de comercio a nivel regional y en algunos casos, fueron funcionarios del ayuntamiento del municipio fronterizo. Por esta razón, en la opinión pública y en sus notas en los periódicos, se conciben como depositarios de la legalidad. Pero, en sus prácticas de cruce, son evidentes los acuerdos establecidos con los representantes locales del Estado para mantener la "flexibilidad para el intercambio". 
En el siguiente relato se nota claramente de qué forma se establece un orden local entre actores de gobierno y traficantes. Lo ejemplificado es cómo algunos traficantes también poseen un rol de miembros de gremios corporativos de partidos políticos, y desde ahí, asumen una posición que trata de mediar entre el negocio del tráfico y los intereses electoreros del partido político. El día 28 de octubre de 2011, por decisión del gobierno federal y con ayuda del ejército mexicano, se tomó la decisión de tirar y desalojar las bodegas ubicadas en la ribera del río Suchiate en Ciudad Hidalgo. La intención era instalar una barda para controlar la erosión que produce el río en épocas de lluvia. En la siguiente nota periodística, publicada un mes después, se exhiben todos los conflictos políticos ocasionados al gobierno municipal de Suchiate por la decisión tomada unilateralmente por el gobierno federal, y paralelamente se patentiza la existencia de la comunidad interpretativa y la compleja trama política a su alrededor:

ii氵Inconformidad por Paso en Suchiate!!! Canceladas rutas alternas, afectan miles de comerciantes.

"Venimos a solicitar que se liberen todos los pasos que originalmente existían por el río Suchiate, para el trabajo de más de mil tricicleros de pasaje y carga del municipio de Suchiate, ya que está habilitado sólo un paso y esto ocasiona problemas entre los diferentes grupos de tricicleros".

Lo anterior fue afirmado en reunión de trabajo en la Secretaría para el Desarrollo de la Frontera Sur y Enlace para la Cooperación Internacional, donde los directos afectados, acuerpados por transportistas y comerciantes pidieron saber quién fue el funcionario que oficializó como único el paso 'El Coyote' que es ilegal. Y no hubo respuesta.

Añadieron, "desde el desalojo del río, cancelaron los pasos [...] mandaron policías del Estado para que nadie trabaje en esa zona y todo se hizo obedeciendo a un grupito cercano al Ayuntamiento, sin tomar en cuenta a los demás sectores que hoy son los grandes afectados".

Los representantes del transporte estatal [...] así como de sindicatos de comerciantes y locatarios de la стм de Suchiate y de la región, afirmaron, "queremos que no haya sólo un paso ilegal oficializado, sino de acuerdo a usos y costumbres se devuelva el paso en todos."

Javier Barrios Huerta, secretario general del Sindicato de Triciclos Rojos de la CTM, puntualizó "los compañeros tricicleros han sido desplazados de su lugar de trabajo y venimos a ver qué está pasando realmente, puesto que se ha internacionalizado al afectar a grupos de tricicleros, balseros y comerciantes del lado de México y de Guatemala”.

Por su parte, Abrahán Téllez, expresó, "todos los líderes presentes nos consideramos aliados estratégicos del gobierno del estado y que siempre hemos apoyado las propuestas como el hecho de que los tricicleros pagaran impuestos y que están dispuestos a negociar con las diferentes partes que se involucran en la problemática.

"Eso sí, no permitiremos que un grupo de 113 comerciantes a los cuales se les indemnizó a la mayoría y que se les entregó un nuevo lugar de trabajo, ahora sean los que negocian la operación en la Riviera del río Suchiate sin tomar en cuenta a los transportistas y demás sectores productivos". 
Los de la Coalición de Organizaciones Sindicales y Sociales de Suchiate, dijeron, "agotamos instancias y esperamos cumplan los compromisos, si no, tomaremos acciones para evitar preferencias y las normas sean parejas para todos. Y damos apoyo a los de la colonia El Carmen, donde dañaron y destruyeron casas en el desalojo de comerciantes" (Cruz, 2011, p. A-8).

Las observaciones del funcionamiento de estos flujos comerciales del lado mexicano comprueban los nexos entre funcionarios, sindicatos y "empresarios", así como otros mecanismos de articulación mediante prácticas como el clientelismo político, pues estos mismos empresarios son líderes o pertenecen a sindicatos o gremios relacionados con partidos políticos como el PRI (Partido Revolucionario Institucional).

Aunque estos empresarios estratégicamente evidencian la falta de control estatal de la frontera y por este motivo justifican los procedimientos acostumbrados de cruce, son ellos quienes reproducen la imagen del Estado como un aparato legítimo de control al cual concurren para resolver sus problemas. Además, al confrontar sus discursos con sus prácticas de introducción, comprobamos que dicha imagen es utilizada, siempre y cuando coincida o esté acorde con sus intereses económicos y no influya de forma negativa en las prácticas de comercio por tráfico hormiga.

\section{Reflexiones finales: Configuración regional del Estado}

Si analizamos la configuración del Estado en las dos dimensiones arriba descritas, en la primera se analiza la manera en que la comunidad interpretativa se finca en las relaciones personales entre empleados de gobierno (estatales y federales), facilitadores del cruce (tricicleros, balseros, buzos), y comerciantes de verdura a pequeña escala. En dichas prácticas se experimentan y se reinterpretan cotidianamente y de forma circunstancial, las categorías jurídicas oficiales con lo chueco y lo derecho. En este sentido, el sistema de Estado visto como gobierno, se basa en relaciones personales, donde se intercalan procedimientos técnicos de cruce mercantil oficiales con lógicas locales sustentadas en la moralidad de las mercancías. La relación entre el personal operativo, facilitadores y estos comerciantes se da por medio de pequeños dones que mantienen la relación entre los involucrados y propician el ambiente de tolerancia característico de la comunidad interpretativa.

En la segunda dimensión, se apela a la flexibilidad legal en relación a la fluidez mercantil diseñada por las negociaciones entre mandos medios de gobierno y "empresarios". Aquí, el Estado es una delgada línea de negociación donde se simula que existe una arena de disputa totalmente antagónica entre empresarios y gobierno. La simulación consiste en anteponerse como grupos antagónicos, donde los traficantes y autodenominados empresarios se enarbolan como representantes de la sociedad civil, haciendo ver sus intereses económicos como los intereses de todos los habitantes fronterizos del lado mexicano, en oposición a los poderes estatales inflexibles y que no captan las lógicas del contexto local. Esta versión de las relaciones de poder en realidad delata cómo lo estatal también es generado por estos grupos de poder, por lo tanto, su producción no se da exclusivamente por el aparato de Estado, sino desde una sociedad civil. Paradójicamente no se asemeja a lo que comúnmente se cree o se idealiza que es la sociedad civil (es decir, un grupo de ciudadanos organizados bajo canales democráticos propiciatorios del Estado de derecho en nombre de todos los habitantes que componen la sociedad nacional); más bien, dentro de esta categoría, se esconden grupos de poder empresarial 
que intentan, mediante sus discursos, representar la voz de la sociedad civil fronteriza. Específicamente son empresarios locales, los cuales, podemos encasillar como poderes tácticos u organizativos siguiendo la tipología de poderes según Eric Wolf (Vease Mintz, 1996, p. 53).

Finalmente, nosotros creemos que eso llamado Estado desde las prácticas de comercio fronterizo no se le percibe como un aparato centralizado, despersonalizado y anónimo, sino que está compuesto por "gente de la región": personal oriundo de los pueblos fronterizos. Es decir, forman parte de la misma sociedad civil a la que supuestamente se impone el orden estatal. Esto implica la incrustación de relaciones personales en las acciones que emprende el personal operativo en nombre del Estado. Bajo estas reflexiones, como Escalona lo analiza en estos ambientes micro políticos, lo que existe es "una problemática combinación entre la comunidad política (Estado) y la sociedad civil que hace ver el Estado como algo más que un aparato burocrático-político-policiaco" (Escalona, 2011, p. 50).

La comunidad interpretativa y el orden de facto creado en su seno en esta frontera, no hace más que evidenciar lo que Abrams (2000) observa del funcionamiento del sistema de Estado. Es decir, el sistema de Estado no es un aparato coherente y centralizado, sino una constelación de intereses con posturas coyunturales; un acuerdo donde "el Estado" sigue siendo una entidad legitimada por la sociedad civil, a pesar de su incapacidad para imponerse. El Estado es un resultado de la práctica política, cuya unidad de fondo se basa en las jugosas ganancias del tráfico hormiga del cual dependen cientos de comerciantes fronterizos.

\section{Referencias}

Abrams, P. (2000). Notas sobre la dificultad de estudiar el 'estado' (Trad. R. Macía y O. Jaramillo). Virajes, (2), 79-98.

Acuerdo que tiene por objeto establecer las reglas conforme a las cuales se otorgarán facilidades migratorias a los visitantes locales guatemaltecos. (12 de marzo de 2008). Diario Oficial de la Federación. Recuperado de http://www.inm.gob.mx/static/Formas_Migratorias/pdf/FMVL.pdf

Appadurai, A. (Ed.). (1991). La vida social de las cosas: perspectiva cultural de las mercancías. México: Conaculta, Grijalbo.

Arriola, A. M. (1995). Tapachula, "la perla del Soconusco", ciudad estratégica para la redefinición de las fronteras. Guatemala: Facultad Latinoamericana de Ciencias Sociales.

Aubry, A. (2006). Las tragedias del Soconusco. Retrospectiva y prospectiva histórica. Revista Contrahistorias. La otra mirada de Clio, (6), 93-108.

Castells, M. y Portes, A. (1989). World underneath: The origins, dynamics, and effects of the informal economy. En A. Portes, M. Castells y L. A. Benton, The informal economy. Studies in advanced and less developed countries (pp. 11-33). Baltimore, Estados Unidos de América: The Johns Hopkins University Press.

Castillo, M. (2002). Región y frontera: la frontera sur de México. Elementos conceptuales para la definición de región fronteriza. En E. Kauffer (Ed.), Identidades, migraciones y género en la frontera sur de México (pp. 19-49). México: El Colegio de la Frontera Sur. 
Cruz, A. de la (25 de noviembre de 2011). iiinconformidad por Paso en Suchiate!!! El Orbe. Recuperado de http://elorbe.com/portada/2011/11/25/\%C2\%A1\%C2\%A1\%C2\%A1-inconformidad-por-paso-en-suchiate.html

Das, V. y Poole, D. (2008). El estado y sus márgenes. Etnografías comparadas. Cuadernos de Antropología, (27), 19-52.

Escalona, J. L. (2011). El incompleto imaginario del orden, la inacabada maquinaria burocrática y el espacio de lucha. Antropología del Estado desde el sureste de México. En A. Agudo, y M. Estrada (Eds.), (Trans)formaciones del estado en los márgenes de Latinoamérica: imaginarios alternativos, aparatos inacabados y espacios transnacionales (pp. 45-87). México: Universidad Iberoamericana de Tijuana, El Colegio de México.

Fletes, H. (2013a). Construyendo la globalización. Estado, mercado y actores de las cadenas agroindustriales de mango desde Chiapas. México: Universidad Autónoma de Chiapas, Conacyt, Ediciones de la Noche.

Fletes, H. (2013b). Estado, infraestructura sociotécnica y poder. La inserción de la sanidad en las cadenas agroindustriales de mango en Chiapas. Carta Económica Regional, (111-112), 19-36. Recuperado de http://cartaeconomica.cucea.udg.mx/administracion/uploads/articulo1080.pdf

Flores, G. (2 de octubre de 2009). Autoridades promueven el tráfico ilegal de mercancías: Canaco. Realizan primer congreso de cámaras del sureste de México y Guatemala. Diario del Sur. Recuperado de http://www.oem.com.mx/diariodelsur/notas/n1347389.htm

Galemba, R. B. (2011). Un poco legal, un poco ilegal; la vida cotidiana en un camino clandestino de la frontera México-Guatemala. En A. Agudo y M. Estrada (Eds.), (Trans) formaciones del estado en los márgenes de Latinoamérica: imaginarios alternativos, aparatos inacabados y espacios transnacionales (pp. 339-369). México: Universidad Iberoamericana de Tijuana, El Colegio de México.

González, J. A. (2009). Comunidades interpretativas. Perspectivas de la hermenéutica literaria de Stanley Fish. ALPHA, (29), 233-249. Recuperado de http://www.scielo.cl/ pdf/alpha/n29/art16.pdf

Lagi, S. (2011). Hans Kelsen: pensador político. Araucaria. Revista Iberoamericana de Filosofía, Política y Humanidades, 13(25), 3-25.

Linares, E. (2010). El Soconusco arqueológico y la costa de Chiapas: historia y patrón de asentamientos [edición especial sobre el Soconusco]. Revista de la Universidad Autónoma de Chiapas, 19-34.

Mariscal, Á. (7 de enero de 2014). Balseros de Chiapas-Guatemala entre la ilegalidad y la sobrevivencia. Chiapas Paralelo. Recuperado de http://www.chiapasparalelo. com/noticias/chiapas/2014/01/balseros-de-chiapas-guatemala-entre-la-ilegalidad-y-la-sobrevivencia/

Mathews, A. S. (2006). Ignorancia, conocimiento y poder. El corte de la madera, el tráfico ilegal y las políticas forestales en México. Desacatos, (21), 135-160.

Mintz, S. (1996). Sabor a comida, sabor a libertad: incursiones en la comida, la cultura y el pasado. México: Centro de Investigaciones y Estudios Superiores en Antropología Social, Consejo Nacional para la Cultura y las Artes de México, Reina Roja.

Ordóñez, C. E. (2007). Economía informal y sistema fronterizo en dos espacios locales en la frontera de Guatemala con México. Geografía Agrícola, (38), 85-100.

Ortiz, G. (s.f.). Ayutla y la legalización de facto del contrabando. Connectas, Plataforma Periodística para las Américas. Recuperado de http://connectas.org/ayutla-y-la-legalizacion-de-facto-del-contrabando/ 
Rojas, H. S. (2015). Cercanías distantes; un análisis de las clasificaciones culturales alrededor del comercio de hortalizas guatemaltecas en México. Revista Devenir, 28(viII) quinta época, 191-220.

Torres, G. (2005). Reseña de "Power, community and the state. The political anthropology of organization in Mexico" de Monique Nuijten. Revista Colombiana de Antropología (41), 266-270. Recuperado de http://www.redalyc.org/articulo. oa?id=105015281010

Voorhies, B. (Ed.) (1991). La economía del antiguo Soconusco. México: Universidad Nacional Autónoma de México, Universidad Autónoma de Chiapas.

\section{Entrevistas}

Antonio. (27 de marzo de 2015). Conversación personal con Hugo Rojas [nota escrita en diario de campo]. Configuración regional del Estado: Orden mercantil y comunidad interpretativa en la frontera México-Guatemala.

Carmen. (Febrero de 2011). Carmen, conversación personal con Hugo Rojas [nota escrita en diario de campo]. Cuando el comercio hace la vida orden negociado, transfiguración del valor y nacionalismo en el contexto fronterizo México-Guatemala (Tesis doctoral). Universidad Iberoamericana, México.

Daniel. (Febrero de 2011). Daniel, empleado de SAGARPA, región VIII Soconusco Chiapas, conversación personal con Hugo Rojas [nota escrita en diario de campo]. Cuando el comercio hace la vida orden negociado, transfiguración del valor y nacionalismo en el contexto fronterizo México-Guatemala (Tesis doctoral). Universidad Iberoamericana, México.

González, R. (Febrero de 2011). Biólogo Rigoberto González, entrevista de Hugo Rojas [cinta en audio]. Cuando el comercio hace la vida orden negociado, transfiguración del valor y nacionalismo en el contexto fronterizo México-Guatemala (Tesis doctoral). Universidad Iberoamericana, México.

Jaime. (30 de marzo 2015). Conversación personal con Hugo Rojas [cinta en audio]. Configuración regional del Estado: Orden mercantil y comunidad interpretativa en la frontera México-Guatemala.

Marco. (2 de abril). Entrevista no estructurada [cinta en audio]. Configuración regional del Estado: Orden mercantil y comunidad interpretativa en la frontera México-Guatemala.

Oficial de inspección Senasica. (7 de abril 2015). Conversación personal con Hugo Rojas [nota escrita en diario de campo]. Configuración regional del Estado: Orden mercantil y comunidad interpretativa en la frontera México-Guatemala.

Ovando, J. (28 de marzo de 2015). Conversación personal con Hugo Rojas [nota escrita en diario de campo]. Configuración regional del Estado: Orden mercantil y comunidad interpretativa en la frontera México-Guatemala.

Salazar, J. L. (7 de abril de 2015). Entrevista de Hugo Rojas [cinta en audio]. Configuración regional del Estado: Orden mercantil y comunidad interpretativa en la frontera México-Guatemala.

Torres, P. (31 de marzo de 2015). Entrevista de Hugo Rojas [cinta en audio]. Configuración regional del Estado: Orden mercantil y comunidad interpretativa en la frontera México-Guatemala. 
Hugo Saúl Rojas Pérez

Mexicano. Doctor en antropología social por la Universidad Iberoamericana, Ciudad de México. Candidato SNI. Actualmente realiza una estancia posdoctoral en el Doctorado de Estudios Regionales de la Universidad Autónoma de Chiapas. Autor de los artículos: "Cercanías distantes; un análisis de las clasificaciones culturales alrededor del comercio de hortalizas guatemaltecas en México" y de "Soltería masculina, familia y ciudadanía en dos pueblos de origen nahua del valle de México", este último en coautoría con Aki Kuromiya. Línea de investigación: identidad, frontera y alimentación.

\section{Héctor Bernabé Fletes-Ocón}

Mexicano. Doctor en Ciencias Sociales con especialidad en Antropología Social por el Centro de Investigación y Estudios Superiores en Antropología Social-Occidente. Maestro en Desarrollo Regional, con especialidad en Reestructuración Productiva. Labora actualmente en la Universidad Autónoma de Chiapas, San Cristóbal de las Casas, Chiapas. Línea de investigación: Estado y globalización agroalimentaria. Publicaciones recientes: coeditor del libro Desarrollo local en México: Iniciativas y miradas en diferentes territorios (2016), y coautor con Alessandro Bonanno del artículo "The processing of palm oil in Chiapas, México: resistance and alternatives", en A. Bonanno y J. S. Barbosa (Eds.). Labor relations in globalized food, Emerald, (2014). 